\title{
Fortification of Carotene from Carrots in Cooking Oil
}

\author{
G. Gurumeenakshi ${ }^{1 *}$, N. Varadharaju ${ }^{2}$, D. Malathi ${ }^{1}$, \\ B. Subbulakshmi ${ }^{1}$ and R. Rajeswari ${ }^{1}$ \\ ${ }^{1}$ Centre for Post Harvest Technology, Agricultural Engineering College \& Research Institute \\ Tamil Nadu Agricultural University, Coimbatore - 641003, India \\ ${ }^{2}$ Agricultural Engineering College \& Research Institute \\ Tamil Nadu Agricultural University, Coimbatore - 641003, India
}

*Corresponding author

\section{A B S T R A C T}

\section{Keywords}

Fortification of

Carotene,

Carrots

Article Info

Accepted:

20 July 2019

Available Online:

10 August 2019
Fortification of food with micronutrients is considered a valid technology and strategy to provide adequate levels of the respective nutrients in the diet, and where the fortified food is highly accessible to the target population. Carrot is a commonly use as vegetable for table purpose and industrial utilization of carrot for the preparation of products is very limited. Dehydrated carrot, carrot powder are some of the commercial carrot products, but not lucarative. Carrot has the most wanted nutrient $\mathrm{b}$ carotene which is a potential ingredient to alleviate vitamin $\mathrm{A}$ deficiency in children. Hence the present study focuses on extraction ,encapsulation of carotene from carrot and fortification in edible oils to address the micro nutrient malnutrition.

\section{Introduction}

Carrot is a versatile root crop with multi purpose use. It is has high nutritive value, antioxidant, anticancerous and medical properties. Micronutrient malnutrition" also known as "hidden hunger" is a global public health problem and affects the quality of human resource development and productivity of the country. Malnutrition in India, particularly among women, children and adolescents is an important issue requiring immediate attention if the country has to have inclusive growth and development. (GOI, 2017). Addressing the global challenge of micronutrient malnutrition requires the need for many strategies - both short- and intermediate-term and long-term sustainable approaches. In addition to the conventional approaches of micronutrient supplementation and fortification, promoting sustainable food based approaches to enable adequate intakes of micronutrients by much of the population. Fortification of food with 
micronutrients is considered a valid technology and strategy to provide adequate levels of the respective nutrients in the diet, and where the fortified food is highly accessible to the target population. Hence the present study focuses on extraction of carotene, encapsulation and fortification in edible oils to address the micro nutrient malnutrition.

\section{Materials and Methods}

\section{Standardization of Extraction method for $\beta$ carotene}

\section{Different extraction methods}

Three different methods for extraction of $\beta$ carotene were identified and performed in the sunlight proof room and the amount of Carotene obtained was determined in each method.

\section{Cold extraction method}

Hundred gram of carrot was weighed and placed in a mortar and crushed with a pestle. Totally $200 \mathrm{ml}$ of the solvent was measured and kept aside and from that $10 \mathrm{ml}$ of solvent was added into the mortar and the sample was crushed. About $5 \mathrm{ml}$ of solvent was added slowly at regular intervals. The solvents were collected separately and was filtered through a filter paper and then transferred into a separating funnel.

To the separating funnel $50 \mathrm{ml}$ of distilled water and $50 \mathrm{ml}$ of $10 \% \mathrm{NaCl}$ solution was added. The mixture was shaken vigorously and kept aside for the layers to separate. The upper layer contained Carotene and it was collected separately. The lower layer was discarded. The extract was stored in amber colored bottles for concentration in a rotary flash evaporator.

\section{Boiling Method}

For extraction, hundred gram of the sample was taken in a round bottom flask and to it $200 \mathrm{ml}$ of solvent was added. The flask was placed in a heating mantle. The contents were heated to facilitate the extraction. After heating for a fixed time (30 minutes) at specific temperatures $\left(50^{\circ} \mathrm{C}\right)$, the extract was filtered and collected in amber colored bottles till concentration.

\section{Soxhlet Method}

The sample(100 g) to be extracted is placed in the Soxhlet extractor. The extractor was connected to the condenser and the round bottom flask. The solvent was heated to reflux, the vapor travel through the passage of the extractor and the condensate dripped back down into the solid material. The solvent filled up the chamber while the material was extracted from the solid. When the solvent volume had almost filled the chamber, the solvents containing the extract flowed back into the round bottom flask through a siphon tube. The process was repeated for a number of cycles and the extract was accumulated in the round bottom flask. After complete extraction, the extract was filtered and collected in amber colored bottles.

\section{Concentration of carotene extract}

Rotary flash evaporator was used to concentrate the extract of the Carotene, by removing the solvent present in it. Solvent present in the solution gets vaporized due to heating and the vapor was condensed by the supplied cold water. After removal of solvent by vaporization the remaining solution was obtained as concentrate.

\section{Estimation of $\beta$ carotene}

The concentrated sample was estimated for 
the amount of $\beta$ carotene. The $10 \mathrm{ml}$ of the sample were taken and made it up to $50 \mathrm{ml}$ with petroleum ether in a standard flask. Ten grams of anhydrous sodium sulphate was added and kept for 30 minutes and the absorbance is read at $453 \mathrm{~nm}$ using petroleum as blank (AOAC 2000)

Carotene content of the sample $=$

OD value of $x$ total volume of sample the sample

Weight of the sample

\section{Standardization of Encapsulation method for $\beta$ carotene}

Microencapsulation of carotene was carried out in a two-step process. The first step was the emulsification of the concentrate and wall material using an emulsifier, followed by spray drying of the resultant emulsion.

\section{Core material}

The concentrated Carotene from Carrot were used as core material. This core material was stored in amber colored bottles in order to protect the concentrate from light and oxygen before conducting the microencapsulation experiments.

\section{Wall material}

Carrier materials lecithin obtained from M/s Himedia Laboratories Pvt. Ltd, Mumbai.

\section{Preparation of emulsion}

The wall : core material ratio was tried in different proportions viz., 1:1, 2:1,3:1,4:1,5:1, $6: 1$.The proportion of wall material, core material, water and emulsifier for the various trials is given in the table below.
Aqueous extract of the wall material was prepared by dissolving malto dextrin/ gum arabic in distilled water at $60^{\circ} \mathrm{C}$ in varying proportions as given in the table. For lecithin a solvent extract using hexane was prepared.

Carotene emulsion was prepared by dissolving the aqueous extract of the wall material to the carotene concentrate. The emulsion formation and stabilization was achieved by using an emulsifying agent (Tween-80) under continuous vigorous agitation. The resultant emulsion was spray dried to obtain encapsulated powder.

\section{Preparation of encapsulated carotene powder from Carrot}

Carotene emulsion (Carrot) was pumped in to the spray drier equipped with the two fluid atomizers. Emulsion was fed into the main chamber through a peristaltic pump at the rate of $5 \mathrm{ml} \mathrm{min}$. The pressure of compressed air for the flow of the spray was adjusted to 5 bars. Air outlet temperature was maintained at $80^{\circ} \mathrm{C}$ and inlet air temperature was $160^{\circ} \mathrm{C}$. The microcapsules were collected and stored in PET bottles till use.

\section{Fortification of encapsulated powder in cooking oil}

The Recommended Dietary Allowance (2010) for $\beta$ carotene is $4800 \mu \mathrm{g}$ per day. The RDA for oil is $25 \mathrm{ml}$ per day. The thumb rule of fortification is the Fortified food should provide only $1 / 3$ of the RDA. This was followed and accordingly $25 \mathrm{ml}$ of oil should provide $1600 \mu \mathrm{g}$ per day. The following table gives the proportion of encapsulated powder and oil for fortification.

\section{Method of fortification}

The method followed for fortification is the premix method, where in a premix of the 
fortificant was developed and this was dissolved in the oil to be fortified.

\section{Development of premix}

For the preparation of the premix $100 \mathrm{ml}$ of the oil/ fat was taken. The proportion of encapsulated powder, oil, temperature for the development of premix is given in the table below.

\section{Preparation of premix}

The oil was heated to $50{ }^{0} \mathrm{C}$ temperature followed by the addition of the encapsulated powder. It was then thoroughly mixed in a magnetic stirrer for 30 minutes for complete dissolving of the powder in the oil and thus the premix was obtained.

The effect of temperature in the dispersion efficiency of the encapsulated powder was studied and presented in the table below.

\section{Addition of premix to the oil}

The premix thus obtained was dissolved to $900 \mathrm{ml}$ of the oil (Mustard/ gingelly). For complete dispersion of the fortificant, this oil was subjected to thorough mixing in a high speed mixer, homogenizer and ultra shear homogenizer with varying time as given below

Sample<smiles></smiles>

High speed mixer (4500 rpm) $30 \mathrm{~min}$

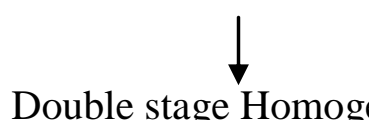
$\left(140 \mathrm{~kg} / \mathrm{cm}^{2}\right) \&$ $\left(115 \mathrm{~kg} / \mathrm{cm}^{2}\right)$<smiles>C[14C](C)=[14CH]</smiles>

Ultra shear homogenizer

$10 \min$ $(20,000 \mathrm{rpm})$

\section{Results and Discussion}

From the above table, it could be inferred that the maximum extraction efficiency of carotene was obtained in cold extraction method, in which hexane is used as a solvent.

The following table summarizes the extraction efficiency of $\beta$ carotene by cold extraction method using hexane as solvent

\section{Recovery of encapsulated powder and its carotene retention}

The recovery of the encapsulated powder and $\beta$ carotene retention in the powder were analysed. Based on the results the best suited wall to core material ratio and the suitable wall material was screened for fortification.

From the above table, it is concluded that, the most suitable ratio of wall material to core 
material was $5: 1$. This is because, apart from the highest recovery of encapsulated powder $(2.5 \mathrm{~g})$ it retained the highest amount of $\beta$ carotene content. Hence this powder was used for further studies

\section{Quality analysis of the fortified oil}

Sedimentation of the fortified oil by centrifuge method

A known quantity of the fortified oil $(50 \mathrm{ml})$ was taken in centrifuge tubes and centrifuged for 30 minutes at $5000 \mathrm{rpm}$. After 30 minutes the volume of the supernatant and the sediment were noted. The sediment was further subjected to ultra filtration and the volume of the filterate $(\mathrm{ml})$ and the weight of the sediment $(\mathrm{g})$ were noted. The results of the supernatant and sediment obtained in the fortified oils subjected to different methods of homogenization are given below.

From the above table it could be observed that, slight sedimentation had occurred in only in high speed mixer, while the samples fortified using the homogenizer and ultra shear homogenizer had no sedimentation. This ensured the complete and uniform mixing of the fortificant in the edible oil.

\section{Physical properties of the fortified oil}

The physical properties of the fortified oil namely the refractive index, bulk density and smoke point of the fortified gingelly/ mustard oil were estimated and presented in the table below.

From the table it could be observed that, the bulk density and refractive index was more for the oil that had been subjected to high speed mixer, when compared to homogenizer and Ultra shear homogeniser. This has also reflected upon the sharp decrease in the smoke point of the oils in homogenizer and ultra shear homogenizer. As a result these two oils will reflect poor cooking quality and the chances for increase in rancidity is also more.

Therefore it was concluded that, Oil samples (Gingelly/ mustard) added with encapsulated Carrot powder with lecithin as wall material, fortified by premix method and homogenized by high speed mixing is the best suited method for fortification of $\beta$ carotene in oil.

\section{Shelf life studies of the fortified oil}

The standardized fortified oil (i.e) Gingelly/ Mustard oil and ghee fortified with encapsulated carrot/ Carrot powder using malto dextrin as wall material, fortified by premix method was subjected to shelf life studies in three different packaging material namely PET jars, Opaque Bi axially Oriented Polypropylene packs and (Opaque BOPP) and HDPE packs and stored at room temperature. The retention of $\beta$ carotene was analysed during storage and the results are presented below.

Table.1 Proportion of contents for the development of premix

\begin{tabular}{|l|c|c|c|c|c|c|c|}
\hline \multirow{2}{*}{ Proportion of contents } & \multicolumn{7}{|c|}{ Wall to core material ratio } \\
\cline { 2 - 7 } & $1: 1$ & $2: 1$ & $3: 1$ & $4: 1$ & $5: 1$ & $6: 1$ \\
\hline Carrot & 2000 & 2000 & 2000 & 2000 & 2000 & 2000 \\
\hline Concentrate $-(\mathbf{m l})$ & 300 & 600 & 900 & 1200 & 1800 & 2000 \\
\hline Distilled water $(\mathbf{m l})$ & 10 & 10 & 10 & 10 & 10 & 10 \\
\hline Emulsifier Tween $-\mathbf{8 0}(\mathbf{m l})$ & 0.33 & 0.66 & 0.99 & 1.32 & 1.65 & 1.98 \\
\hline Wall material - (mg) (Lecithin) & 300 & 600 & 900 & 1200 & 1800 & 2000 \\
\hline Hexane (ml) & & & & & & \\
\hline
\end{tabular}


Table.2 Proportion of ingredients and temperature for the development of premix

\begin{tabular}{|l|c|}
\hline Oil / source of $\beta$ carotene & \\
\hline Gingelly oil / Mustard oil & \\
\hline Encapsulated powder (L) -g & 0 \\
\hline
\end{tabular}

Encapsulated powder (L) - Lecithin

Table.3 Efficiency of extraction of $\beta$ carotene by different methods and solvents

\begin{tabular}{|c|c|c|c|c|c|c|c|c|c|c|c|}
\hline \multirow[t]{2}{*}{ Extraction Method } & \multirow[t]{2}{*}{$\begin{array}{c}\text { Sample } \\
(\mathbf{1 0} \\
\mathbf{K g})\end{array}$} & \multicolumn{2}{|c|}{ Acetone } & \multicolumn{2}{|c|}{ Hexane } & \multicolumn{2}{|c|}{$\begin{array}{l}\text { Acetone: } \\
\text { Hexane } \\
(50: 50)\end{array}$} & \multicolumn{2}{|c|}{ Ethanol } & \multicolumn{2}{|c|}{$\begin{array}{l}\text { Ethyl } \\
\text { acetate }\end{array}$} \\
\hline & & $\begin{array}{c}\mathrm{A}^{*} \\
(\mathbf{m g})\end{array}$ & $\begin{array}{c}\mathbf{E}^{*} \\
(\%)\end{array}$ & $\begin{array}{c}\mathbf{A}^{*} \\
(\mathbf{m g})\end{array}$ & $\begin{array}{c}\mathbf{E}^{*} \\
(\%)\end{array}$ & $\begin{array}{c}\mathrm{A}^{*} \\
\text { (mg) }\end{array}$ & $\begin{array}{l}\mathbf{E}^{*} \\
(\%)\end{array}$ & $\begin{array}{c}\mathbf{A}^{*} \\
(\mathbf{m g})\end{array}$ & $\begin{array}{c}\mathbf{E}^{*} \\
(\%)\end{array}$ & $\begin{array}{c}\mathbf{A}^{*} \\
(\mathbf{m g})\end{array}$ & $\begin{array}{l}E^{*} \\
(\%)\end{array}$ \\
\hline Cold & Carrot & 436 & 73 & 450 & 75 & 425 & 71 & 412 & 69 & 400 & 67 \\
\hline Traditional boiling & Carrot & 253 & 42 & 265 & 44 & 246 & 41 & 241 & 40 & 232 & 39 \\
\hline Soxhlet & Carrot & 290 & 48 & 300 & 50 & 285 & 48 & 270 & 45 & 260 & 43 \\
\hline
\end{tabular}

\begin{tabular}{|l|c|}
\hline & Carrot \\
\hline Availability of $\boldsymbol{\beta}$ carotene $\mathbf{1 0 0} \mathbf{g}$ & $6.00 \mathrm{mg}$ \\
\hline Availability of $\boldsymbol{\beta}$ carotene / $\mathbf{1 0} \mathbf{~ k g}$ & $600 \mathrm{mg}$ \\
\hline Extract obtained from $\mathbf{1 0} \mathbf{~ K g}$ & 4 litres \\
\hline $\boldsymbol{\beta}$ carotene obtained in $\mathbf{4}$ litres of the extract & $450 \mathrm{mg}$ \\
\hline Extraction efficiency & $75 \%$ \\
\hline Concentrate obtained from $\mathbf{4}$ litres & 2 litres \\
\hline $\boldsymbol{\beta}$ carotene in 2 litres of concentrate & $450 \mathrm{mg}$ \\
\hline
\end{tabular}

Table.4 Recovery of encapsulated powder and its carotene retention

\begin{tabular}{|l|c|c|c|}
\hline Source & Proportion & \multicolumn{2}{|c|}{ Lecithin } \\
\cline { 2 - 4 } & & Powder $(\mathbf{g})$ & $\boldsymbol{\beta}$ carotene $(\mathbf{m g})$ \\
\hline \multirow{3}{*}{ Carrot } & $1: 1$ & 0.9 & 144 \\
\cline { 2 - 4 } & $2: 1$ & 1.35 & 216 \\
\cline { 2 - 4 } & $3: 1$ & 1.80 & 288 \\
\cline { 2 - 4 } & $4: 1$ & 2.25 & 360 \\
\cline { 2 - 4 } & $5: 1$ & 2.5 & 400 \\
\hline
\end{tabular}


Table.5 Physical properties of the fortified oil

\begin{tabular}{|l|c|c|c|}
\hline Sample/ Property & $\begin{array}{l}\text { High speed } \\
\text { mixer }\end{array}$ & Homogeniser & $\begin{array}{l}\text { Ultrashear } \\
\text { homogeniser }\end{array}$ \\
\hline Gingelly oil & & \\
\hline Encapsulated Carrot powder \\
\hline Refractive index & 1.4730 & 1.4024 & 1.3515 \\
\hline Bulk density & 0.9240 & 0.9231 & 0.9210 \\
\hline Smoke point & $162^{\circ} \mathrm{C}$ & $154^{\circ} \mathrm{C}$ & $149^{\circ} \mathrm{C}$ \\
\hline Mustard oil & & \\
\hline Encapsulated Carrot powder & & \\
\hline Refractive index & 1.4760 & 1.4745 & 1.4730 \\
\hline Bulk density & 0.9270 & 0.9251 & 0.9201 \\
\hline Smoke point & $230^{\circ} \mathrm{C}$ & $221^{\circ} \mathrm{C}$ & $215^{\circ} \mathrm{C}$ \\
\hline
\end{tabular}

Table.6 Retention of Carotene in different packaging material during storage (mg/litre)

\begin{tabular}{|c|c|c|c|c|c|c|c|}
\hline Sample & \multicolumn{2}{|c|}{ PP pouches } & \multicolumn{2}{c|}{ PET Bottles } & \multicolumn{2}{c|}{ Opaque BOPP } \\
\hline & $0^{\text {th }}$ day & $60^{\text {th }}$ day & $0^{\text {th }}$ day & $60^{\text {th }}$ day & $0^{\text {th }}$ day & 60 day \\
\hline \multicolumn{7}{|c|}{ Carotene fortificant from Carrot } \\
\hline Mustard oil & 64.162 & 64.138 & 64.162 & 64.148 & 64.162 & 64.156 \\
\hline Gingelly oil & 64.128 & 64.089 & 64.128 & 64.112 & 64.128 & 64.119 \\
\hline Ghee & 64.206 & 64.164 & 64.206 & 64.180 & 64.206 & 64.193 \\
\hline
\end{tabular}

Table.7 Sedimentation Value of Fortified Oils

\begin{tabular}{|c|c|c|c|c|c|c|}
\hline \multirow{2}{*}{$\begin{array}{l}\text { Oil } \\
\text { Source of } \\
\beta \text { Carotene }\end{array}$} & \multicolumn{2}{|c|}{$\begin{array}{l}\text { High speed mixer } \\
\text { (30 mins) }\end{array}$} & \multicolumn{2}{|c|}{ Homogenizer } & \multicolumn{2}{|c|}{$\begin{array}{c}\text { Ultra shear homogenizer } \\
\text { (30 mins) }\end{array}$} \\
\hline & $\mathbf{S}_{1}$ & $\mathbf{S}_{2}$ & $\mathbf{S}_{1}$ & $\mathbf{S}_{2}$ & $\mathbf{S}_{1}$ & $\mathbf{S}_{2}$ \\
\hline Gingelly oil & 49.970 & 0.028 & 50 & - & 50 & - \\
\hline Mustard oil & 49.96 & 0.035 & 50 & - & 50 & - \\
\hline
\end{tabular}

$\mathrm{S}_{1}$ - supernatant $\mathrm{S}_{2}$ - sedimentation 
Table 6 vividly indicates that the maximum retention of $\beta$ carotene was found in Opaque BOPP packs irrespective of the oil and the fortificant even at 60 days of storage at ambient conditions.

Summary and conclusion are as follows:

The most efficient method of extraction of $\beta$ carotene from Carrot is by Cold extraction method using hexane as the solvent The amount of $\beta$ carotene present in the 4.0 litres of extract is $450 \mathrm{mg}$. Effective concentration of the extract was achieved by rotary flash evaporator. The most suitable wall material for encapsulation is lecithin in the ratio 5:1 Spray drier with an inlet temperature of $160^{\circ} \mathrm{c}$ and Outlet temperature of $90^{\circ} \mathrm{c}$ was most effective to obtain the encapsulated powder. The yield of encapsulated powder contained was $2.50 \mathrm{~g}$ containing $400 \mathrm{mg}$ of $\beta$ carotene. In terms of addition of encapsulated powder one litre of oil contained $0.40 \mathrm{~g}$ of Carrot powder. The most suitable method of fortification is premix method followed by high speed mixing. Storage stability -60 days in Opaque BOPP packs.

\section{References}

AOAC. (2000) Official Method of Analysis. 17th edition. Association of Official Analytical Chemists. Maryland.

Government of India. (2017) Nourishing India: National Nutrition Strategy. Niti Aayog

Gopalan C., Ramasastri B.V. and Balsubramaniyan S.C. (2004) Nutritive value of Indian Foods. National Institute of Nutrition. Hyderabad. India, 20-50.

Ranganna S. (1995) Manual of analysis of fruits and vegetable products. Tata Mc Graw Hill Publishing Co., Ltd., New Delhi, 71.

Rangaswamy R. (1995) Randomized Complete Block Design. A Text book of Agricultural Statistics. New Age International Publishers, New Delhi, 281.

\section{How to cite this article:}

Gurumeenakshi, G., N. Varadharaju, D. Malathi, B. Subbulakshmi and Rajeswari, R. 2019. Fortification of Carotene from Carrots in Cooking Oil. Int.J.Curr.Microbiol.App.Sci. 8(08): 2547-2554. doi: https://doi.org/10.20546/ijcmas.2019.808.296 